\title{
An OpenFOAM simulation of the natural ventilation system in a university chemical laboratory
}

\author{
Córdova-Suárez, $M^{1, *}$, Tene-Salazar, $O .{ }^{4}$,Tigre-Ortega, $F .{ }^{2}$, Carrillo-Ríos, $S .{ }^{2}$, Córdova-Suárez, $D .{ }^{3}$, Tapia- Vasco, $L .{ }^{1}$, \\ and Quesada-Revelo, $D^{1}$ \\ ${ }^{1}$ Technical University of Ambato (UTA) School of Food Science and Engineering. Ambato (Ecuador) \\ ${ }^{2}$ Technical University of Ambato (UTA) School of Systems, Electronics and Industrial Engineering. Ambato (Ecuador) \\ ${ }^{3}$ HES WELL CORDINATOR SCHLUMBERGER SPM-SHAYA, Quito (Ecuador) \\ ${ }^{4}$ Technical University of Ambato (UTA) School of Mechanical Engineering. Ambato (Ecuador)
}

\begin{abstract}
The indoor airflow with a natural ventilation system was numerically calculated using the laminar and turbulent approach. In the chemical laboratory of the Technical University of Ambato, the computational code OpenFoam demonstrated an ability to numerically predict flow patterns. The design contemplated the natural ventilation system considering the laboratories' working conditions not only in summer, but also in a winter week. These two operating conditions are calculated on a fully open and closed environment. For a room with a capacity of 20 people, the climate data average values were recorded at $14.0^{\circ} \mathrm{C}, 81.7 \%, 1.7 \mathrm{~m}$ $/ \mathrm{s}$ for temperature, relative humidity, and wind speed, respectively. Furthermore, the demonstration has shown that the homogeneous occupancy air speed average is was $0.7 \mathrm{~m} / \mathrm{s}$ with a facade air intake of $1.0 \mathrm{~m} / \mathrm{s} 0.6 \mathrm{~m}$ / $\mathrm{s}$ in the room valid for the exchange of air and evacuation of pollutants. The maximum pressures were found in the lower part of the laboratory. This prevents the modification of the thermo-hygrometric conditions.
\end{abstract}

\section{Introduction}

The ventilation in a workplace is a powerful instrument for maintaining acceptable Indoor Air Quality (IAQ). (The (IAQ) of a workplace play a crucial role and it had a large impact on the comfort and health of its occupants [1]. The natural ventilation has the advantage of achieving high ventilation rates for the fresh air and cooling supply, however, it does not have the capacity of air for the winter heat recovery [2].That said, the energy saving and low maintenance costs will determine the potential application of this technique.

In practice, The (IAQ) of a chemical laboratory is determined not only by its natural or forced ventilation system, but also by its structural configuration to avoid chemical exposure [1]. Besides that, the thermoshygrometric factors and the, exposure to chemicals substances also play a significant role in (IAQ) [3].

From the two best known types of natural ventilation systems; the single-side and cross flow ventilation, the single-sided ventilation is suitable to be used in the building with large areas and one outside opening, despite of their lower efficiency [3]. On the other hand, the (IAQ) management and thermal comfort in occupants with a high use of chemical contaminants is still inefficient. This issue is due to the lack of budget, reduced used of space and incorrect distribution of the useful spaces [4].
IAQ can be improved by acting on the laboratory conditions. It is therefore recommended to design an independent air conditioning system [5]. To study the buildings' climate operation, an energy simulation approach called Open-source Field Operation and Manipulation (OpenFOAM) was used. This approach was adopted for the domain of Heating, Ventilation and Air Conditioning (HVAC) [6].

OpenFOAM is a free and open-source computational code, which demonstrate an ability to predict flow pattern and thereby, solving the ventilation research problems [7]. It has interfaces that support a related data management across all environments and makes it easier to obtain a satisfactory performance [8]. To perform an efficient and accurate simulation using Computational Fluid Dynamics (CFD), you must choose the most suitable model. Therefore validation studies are imperative [9].

As the contaminants concentration in chemical laboratories of Technical University of Ambato (UTA) had exceeded the comfort limits established in ISO 171330-2: 2009 , especially the carbon dioxide (CO2) [10], this work will serve as a baseline to determine the appropriate control measures for their IAQ.

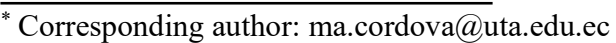




\section{Theoretical framework}

\subsection{OpenFOAM}

The Open-source Field Operation and Manipulation software (OpenFOAM) has some elements that can be adopted for static and thermal linear structural analysis. In fact, it is a specialized software designed for modeling fluid dynamics problems with finite-volumes. Furthermore, it has an user interface, although its main objective is oriented to be a library for programming problems CFD (Computational Fluid Dynamics) in C ++ language. [11]

\subsection{Natural ventilation}

Natural ventilation depends on two principles related to fluid mechanics, thermal buoyancy and air velocity. [12]

\subsection{Natural ventilation strategies}

\subsubsection{Unilateral ventilation}

Taking advantage of the thermal buoyancy effect with openings on one side of the facade only, the air supply could enter the room on the same side when the air is extracted. To take advantage of its benefits, openings are installed in the façade and distributed at different heights [13].

\subsubsection{Crossed ventilation}

As there are air flows between two opposing facades, it is necessary to implement windows or fans on the front entrance and exit of air. They have the function of distributing the air [14].

\subsubsection{Solar chimney}

It is a strategy designed to remove air from a room without influence of air direction [15].

\subsubsection{Double facade}

By constructing a double-wall the cavity formed by the double-wall is used as an air channel [16] and could serve as an isolation mechanism inward.

\subsection{Laboratory ventilation}

Assuming there is a ventilation system that establishes a directional flow to the laboratory, the building ventilation system must be constructed so that the air containment laboratory - Biosafety Level 3 is not directed to other areas of the building. The air can then be filtered by a reconditioned and recirculated High- efficiency particulate air (HEPA) system, within the laboratory. When the laboratory air is expelled directly out from the building. it should be dispersed away from the occupied buildings and air intakes. Depending on the agents one is working with, the air can be discharged through HEPA filters [17].

\section{Methodology}

The input configuration HVAC using the computational code OpenFOAM follows the five steps as defined in the flow chart described in Figure 1.

\section{START}

climatological characteristics:

Temperature, relative humidity, wind speed.

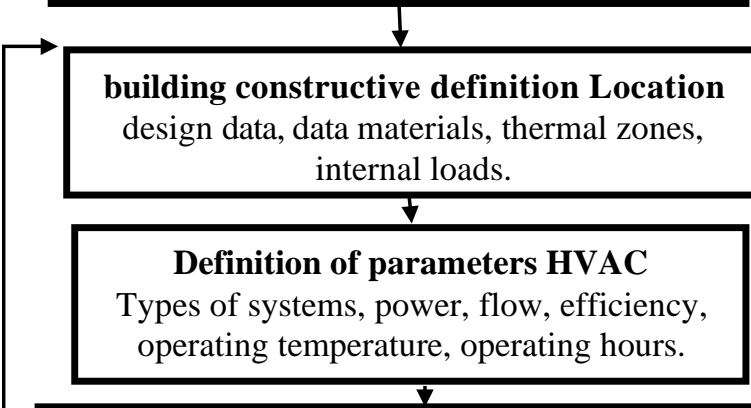

Simulation with OpenFOAM

Development of the simulation model HVAC.

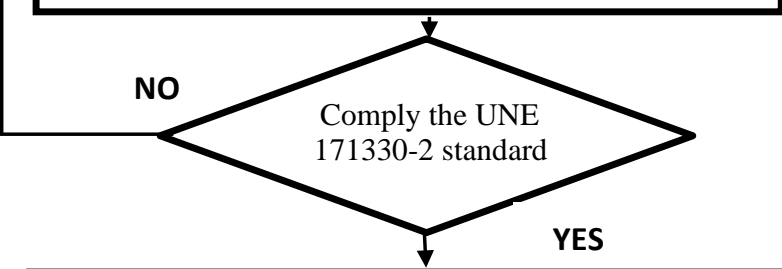

Document the configuration

Define the best configuration of materials and classroom model.

\section{END}

Fig. 1. Flow chart to simulate natural ventilation with OpenFOAM

In the data pre-processing stage, the climatological characteristics are entered, then the building types specification is determined for the building parameters HVAC. Thereafter, each of the simulation is referred to validate the proposed model and determine the quality standard indoor air UNE 171330-2.

\subsection{Climatic conditions of the province of Tungurahua}

In the Tungurahua province, it can be observed that the climate is characterized by average temperatures of $20^{\circ} \mathrm{C}$ most of the year (see Figure 2). There are no significant fluctuations in the day, but there will be heating needs at night (Palme et al., 2015).

The temperature and humidity conditions' data were taken from information provided by the Meteorological Network (RME) of the Honorable Provincial Government of 
Tungurahua located at the airport in Izamba-Ambato at a distance of $2 \mathrm{~km}$ away from the laboratory location.

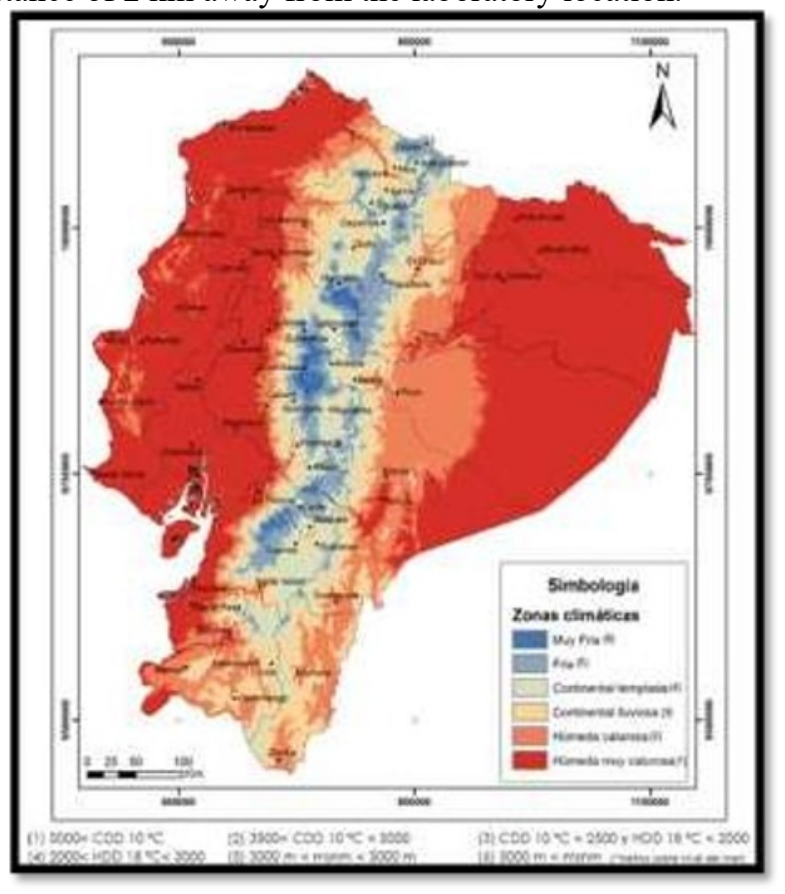

Fig. 2. Climatic zoning map of Ecuador and thermal criteria. Taken from (Palme et al., 2015).

In this investigation, the temperature, relative humidity and wind velocity are determined by three values, namely the maximum, minimum and average values as provided by RME [18].

\subsection{Building constructive definition}

An adequate selection of the materials to be used in construction is necessary [19] in managing the energy flows to increase the user comfort and get a smart ecosystems. [20] In cold climates, the time period that the material performs energy exchange process is directly related to the thickness [21].

In this work, the components laboratory such as: walls, partitions and windows with their respective overall composition and convection coefficient were determined. [22]

\subsection{Definition of parameters Heating and Air Conditioning}

The laboratory type in this research is designed under the necessary means to carry out experiments, scientific works or technical nature investigations.

In order to reduce the energy costs related to electrical energy, operation and maintenance, a natural ventilation system is designed for the laboratory type [23] and also to comply with the Safety and Health at Work legislation.

In this work, the laboratory façade orientation is considered with respect to the north for the use of natural light. Additionally, the form, the type, the distribution and the number of people (20 students) of the project are reproduced to complement with the HVAC system adequacy.

\subsection{Simulation with OpenFOAM}

To study climate and energy performance of the building, OpenFOAM is used.

First, flow lines will be determined in the laboratory and then the speed of stay inside the laboratory is determined, so that later the temperature distribution in the $\mathrm{YZ}$ and $\mathrm{XZ}$ planes that meet the conditions mentioned (IAQ) UNE 171330-2 is found. If conditions do not suit what is mentioned in the standard configuration type, the laboratory construction conditions changes.

Different scenarios work day and night conditions are considered to perform the simulations shown in Table 1.

Table 1. Laboratory conditions' scenarios to carry out the simulation

\begin{tabular}{|c|c|}
\hline $\begin{array}{c}\text { Reference } \\
\text { Simulation }\end{array}$ & Description \\
\hline scenario A1 & closed laboratory \\
\hline A1.1 & $\begin{array}{c}\text { Laboratory closed day } \\
(12: 00 \mathrm{am})\end{array}$ \\
\hline A1.2 & $\begin{array}{c}\text { Laboratory closed night } \\
(7: 00 \text { p.m. })\end{array}$ \\
\hline scenario B1 & open lab \\
\hline A1.1 & Open lab day (12:00 am) \\
\hline A1.2 & Open lab night (7:00 p.m.) \\
\hline
\end{tabular}

Note: The simulations are carried for both cases under the same conditions and material parameters and number of people.

a Thermal load values, materials and radiation conditions are obtained from the database simulation program

\section{Results}

\subsection{Outside weather conditions results}

Table 2 presents averaged humidity conditions' representative results for the chemical laboratory type location with coordinates: $01^{\circ} 16^{\prime} 7.2^{\prime}$ 'south latitude (S) and $78^{\circ} 37^{\prime} 29.30$ " West Longitude (W). Elevation. $2725 \mathrm{~m}$ a.s.1..

The average value of the specific humidity conditions exceed the ranges established by the ISO 171330-2 UNE standard. In other words, these values exceed the temperature and the relative humidity in environments with a metabolic activity rate of 1.2 met, clothing grade of 0.5 clo in summer and 1 clo in winter with a satisfaction predicted percentage (PSP) of $10 \%$.

Table 2. Summary table of weather data (Ambato Airport weather station)

\begin{tabular}{|c|c|c|c|}
\hline Parameter & $\begin{array}{c}\text { Temperature } \\
\left({ }^{\circ} \mathrm{C}\right)\end{array}$ & $\begin{array}{c}\text { Humidity } \\
(\%)\end{array}$ & $\begin{array}{c}\text { Wind } \\
\text { speed } \\
(\mathrm{m} / \mathrm{s})\end{array}$ \\
\hline Maximum & 16.7 & 90.2 & 2.8 \\
\hline Minimum & 12.2 & 67.4 & 1.0 \\
\hline Average & 14.0 & 81.7 & 1.7 \\
\hline
\end{tabular}

Note: The descriptive statistics are presented for each of the levels of the independent variable, and for the whole sample. 


\subsection{Building construction results}

Table 3 shows the results of the building structural conditions obtained in the OpenFOAM software.

Table 3. Summary Table of construction data for chemical and computer laboratories

$$
\mathbf{m}^{2}{ }^{\circ} \mathrm{K}
$$

\begin{tabular}{|c|c|c|}
\hline Element & Composition & $\overline{\mathrm{U} \text { a }(\mathbf{W} /())}$ \\
\hline Walls & $\begin{array}{l}\text { Brick } 1 \mathrm{~cm} \text {; hollow } \\
\text { ceramic block } 14 \\
\mathrm{~cm} \text {; unventilated air } \\
\text { chamber } 1 \mathrm{~cm}\end{array}$ & 0,87 \\
\hline Divisions & $\begin{array}{c}\text { 2x laminated } \\
\text { plasterboard } 1 \mathrm{~cm} \text {; } \\
\text { unventilated air } \\
\text { chamber } 1 \mathrm{~cm} ; \\
\text { Hollow ceramic } \\
\text { block } 14 \mathrm{~cm} \text {; } \\
\text { unventilated air } \\
\text { chamber } 1 \mathrm{~cm} ; 2 \mathrm{x} \\
\text { laminated } \\
\text { plasterboard } 1 \mathrm{~cm}\end{array}$ & 0,97 \\
\hline Glasses & $\begin{array}{c}\text { glass } 6 \mathrm{~mm} \text { (single } \\
\text { glass), aluminum } \\
\text { frame }(2 \mathrm{~cm}) \text { without } \\
\text { thermal break } \\
\text { protection inside with } \\
\text { opaque } \\
\text { light gray }\end{array}$ & 5.8 \\
\hline
\end{tabular}

Note: The materials described specify characteristics for elements used for construction. $\mathrm{U}=$ thermal transmittance. Thermal load values are obtained from the database OpenFoam simulation program.

The highest value of the thermal transmittance is gotten by glasses, because of its material characteristics. All values are within the NTE INEN standard 15927-1: 2013 specifications.

\subsection{Definition of parameters results of heating, ventilation and air conditioning}

Figure 3 shows the chemical laboratory type. Also, parameters determined by previous studies about the type of optimal lighting conditions for chemical laboratories from the Technical University of Ambato (UTA) [24], where 7 parameters were defined as openFOAM imput as well as: the activity, the dimensional configuration, the openings, the lighting, the HVAC, the CFD and the results options.

The laboratory type setting is adjusted to the temperature and humidity conditions described in Table 2 and the thermal transmittances value determined in Table 3 is not a model for other similar establishments conditions outside the UTA.

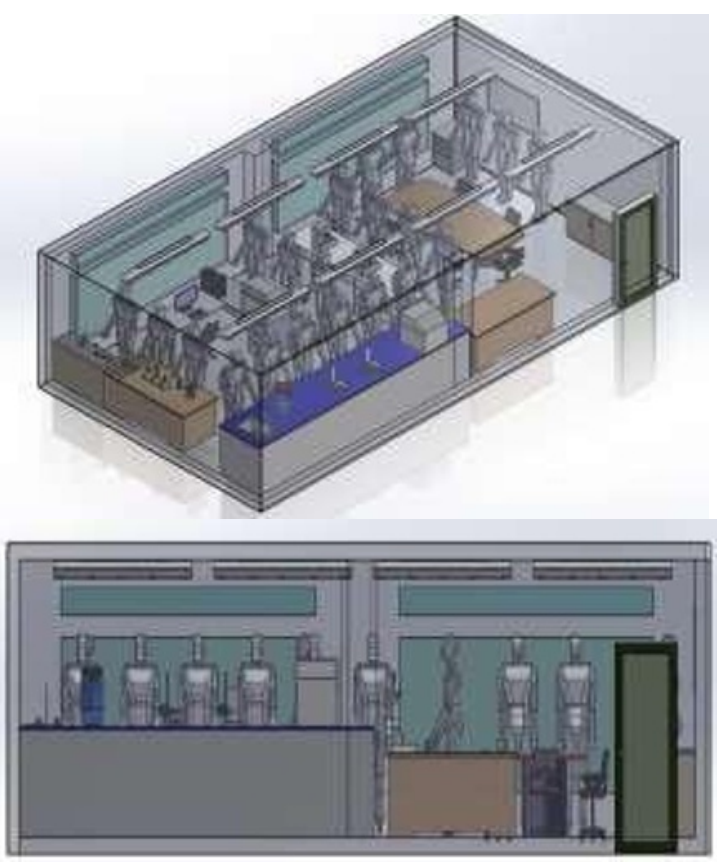

Fig. 3. Configuration UTA chemical laboratory model type.

\subsection{Simulation with OpenFOAM}

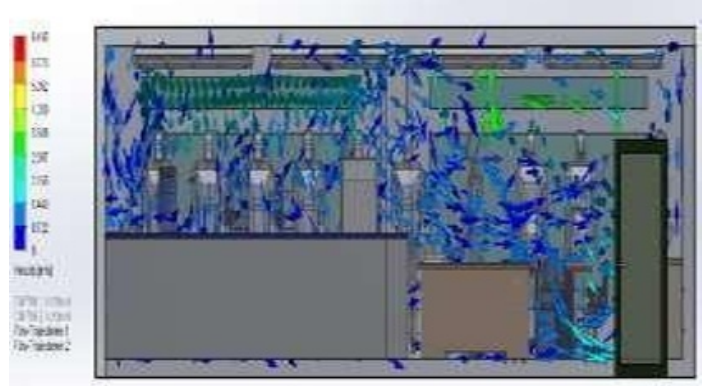

Fig. 4. Cloud flow lines image inside the laboratory

Figure 4 illustrates the flow trajectories during the simulation in the chemical laboratory. Additionally, the colours indicate the velocity parameters used.

\subsection{Temperature distribution in the planes $\mathrm{YZ}$ and \\ $\mathrm{X}$.}

The cloud illustrates the maximum and minimum temperature values inside the room. The minimum temperature is $20.5^{\circ} \mathrm{C}$ and the maximum is found at the top of the walls (See Figure 5).

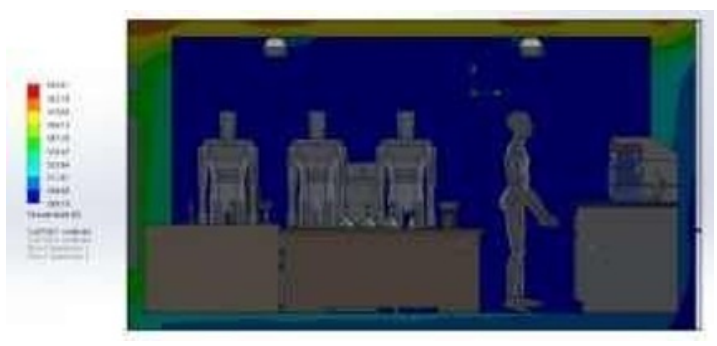

Fig. 5. Field cloud temperature image. $X Z$ and $Y Z$ plane cutting 
The homogeneous average temperature inside to simulated weather conditions for several hours a day and extreme conditions of occupants in the classroom is $23^{\circ} \mathrm{C}$, within the range ( 17 to $27^{\circ} \mathrm{C}$ ) set by the UNE $171330-2$.

\subsection{Internal pressures distribution in the $X Z$ and $Y Z$ planes}

The design verifies that the maximum pressures are at the bottom of the laboratory type studied.This gives control and standardize the contaminated air entry, moisture (the aim is to minimize that entry to avoid instruments oxidation) and thereby prevent measurements altered by modifying thermohydrometer conditions . (See Figure 6)

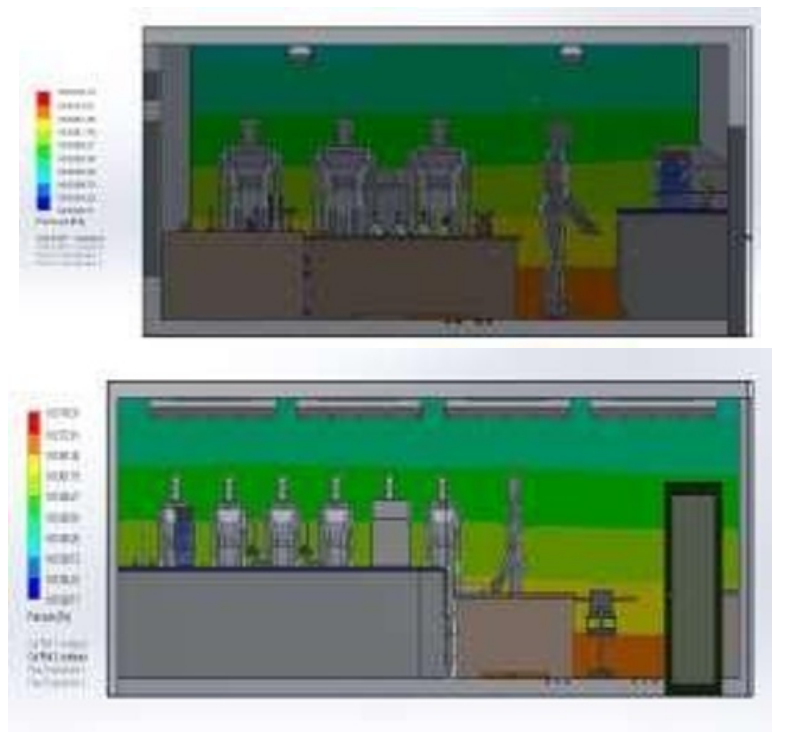

Fig. 6. Field cloud temperature picture. $X Z$ and $Y Z$ plane cutting

\section{Discussion}

The constructive conditions reflect the reality of the majority of pollution measurement results in interior spaces in these workplaces. The activities performed under these conditions are complicated because not only that there are no recirculating air conditions, chemicals that are used to perform chemical practices are stored on the shelves and under the tables.

\section{Conclusions}

The indoor air flow simulation was studied numerically using the computational code Open FOAM. The results obtained for the UTA chemical laboratory type of room for climatic conditions were $14^{\circ} \mathrm{C}$ temperature, $81.7 \%$ relative humidity and $1.7 \mathrm{~m} \mathrm{/} \mathrm{s} \mathrm{wind} \mathrm{speed,} \mathrm{determine} \mathrm{an}$ homogeneous average speed wind occupation of $0.7 \mathrm{~m} / \mathrm{s}$ complying with the values of comfort from the NTE INEN 1126: 1986 standard.

The indoor air quality and the ISO 171330-2 will benefit from air renewal with natural ventilation when it reaches an air velocity value of $1.0 \mathrm{~m} / \mathrm{s}$ to $0.6 \mathrm{~m} / \mathrm{s}$ in the workplace. Although, there is no significant weather conditions difference in winter and summer. Therefore, it is recommended to work in an open-door laboratory way.

The results have shown that it is possible to maintain an acceptable comfort temperature from time to time, which unfortunately, has not been achieved at all. The inner region is able to reach thermal comfort rather than the intermediate region, confirming that the use of the proposed material have meet part of its aim in keeping the temperature constant with respect to the intermediate zone and the outer weather determined in UNE-EN ISO 7730 standard.

\section{References}

1. E. Gadena, X. Guardino, M. Rosell, and J. Silva, " NTP 550: Prevención de riesgos en el laboratorio: ubicación y distribución," ed, 1994, p. 5.

2. T. Schulze, D. Gürlich, and U. Eicker, "Performance assessment of controlled natural ventilation for air quality control and passive cooling in existing and new office type buildings," Energy and Buildings, vol. 172, pp. 265-278, 2018.

3. P. Karava, T. Stathopoulos, and A. K. Athienitis, " Wind-induced natural ventilation analysis," Solar Energy, vol. 81, pp. 20-30, 2007.

4. V. Mujica and C. Pérez, "Evaluación de impactos ambientales en el Laboratorio de Ingeniería Química de la Universidad de Carabobo," INGENIERÍA UC, vol. 12, p. 10, 2005.

5. A. P. Borja Suárez, "Estudio de instalaciones de sistemas de computación y diseño de un laboratorio prototipo para un centro de educación," QUITO: EPN, 1990, 1990.

6. A. Limane, H. Fellouah, and N. Galanis, "Threedimensional OpenFOAM simulation to evaluate the thermal comfort of occupants, indoor air quality and heat losses inside an indoor swimming pool, " Energy and Buildings , vol. 167, pp. 49-68, 2018.

7. M. S. M. Ali, L. L. Leong, M. N. Ramly, S. A. Z. Shaikh, and S. Muhammad, "Utilizing open source software running in inexpensive high performance computing system for cfd applications," ARPN vol. 12, pp. 3061-3067, 2017.

8. M. Balogh, A. Parente, and C. Benocci, "RANS simulation of $A B L$ flow over complex terrains applying an Enhanced $k-\varepsilon$ model and wall function formulation: Implementation and comparison for fluent and OpenFOAM," J. W. E. and Indus. Aerodyna., vol. 104-106, pp. 360-368, 2012.

9. N. F. M. Kasim, S. A. Zaki, M. S. Mat Ali, A. F. Mohammad, and A. Abd Razak, "A verification and validation study of CFD simulation of wind-induced ventilation on building with single-sided opening," in Applied Mechanics and Materials vol. 554, ed, 2014, pp. 696-700. 
10. M. Córdova, P. Martínez, and T. Saltos, "Evaluación de la Calidad de Aire en los Laboratorios de la Universidad Técnica de Ambato," U.T.A. 2016.

11. O. OpenCFD, "The open source CFD toolbox," User Guide, OpenCFD Ltd, vol. 770, (2009).

12. B. Correa, R. David, and J. P. Kastillo Estévez, "Optimización energética para el aprovechamiento de ventilación natural en edificaciones en climas cálidos de Ecuador," Quito, 2015.,( 2015).

13. T. Kleiven, Natural ventilation in buildings: architectural concepts, consequences and possibilities: Institutt for byggekunst, historie og teknologi, (2003).

14. M. Santamouris and P. Wouters, Building Ventilation: The state of the art: Routledge, 2006.

15. B. R. Hughes, J. K. Calautit, and S. A. Ghani, " The development of commercial wind towers for natural ventilation: A review," Applied Energy, vol. 92, pp. 606- 627, (2012).

16. N. Mingotti, T. Chenvidyakarn, and A. W. Woods, "The fluid mechanics of the natural ventilation of a narrow- cavity double-skin facade," Building and environment, vol. 46, pp. 807-823, 2011.

17. W. H. Organization, "Manual de bioseguridad en el laboratorio," 2005.

18. I. E. d. N. (INEN), "NTE INEN 1126: Ventilación natural de edificios.," in Requisitos, ed, (1984).

19. H. Lee and A. Ozaki, "Sensitivity analysis for optimization of renewable-energy-based aircirculation-type temperature-control system," Applied Energy, vol. 230, pp. 317-329, 2018.

20. R. Bruno, N. Arcuri, and G. Cuconati, " A smart airconditioning plant for efficient energy buildings," in Internet of Things vol. Part F2, ed, 2019, pp. 251-274.

21. M. Palme, A. Lobato, A. Gallardo, R. Beltrán, J. Kstillo, G. Villacreses, et al., "Estrategias para mejorar las condiciones de habitabilidad y el consumo de energía en viviendas," ed, 2015, p. 64.

22. [22] I. E. d. N. (INEN), "NTE INEN 15927-1. COMPORTAMIENTO HIGROTÉRMICO DE EDIFICIOS. CÁLCULO Y PRESENTACIÓN DE DATOS CLIMÁTICOS. PARTE 1," in MEDIAS MENSUALES DE ELEMENTOS METEREOLÓGICOS SIMPLES , ed, 2013, p. 29.

23. E. Gadena, X. Guardino, M. Rosell, and J. Silva, "NTP 551: Prevención de riesgos en el laboratorio: la importancia del diseño," ed, 2000, p. 6.

24. A. Morejón and M. Córdova, "Condiciones de iluminación que inciden en el confort visual de los ocupantes de laboratorios de la Universidad Técnica de Ambato - Campus Huachi," Master, Universidad Técnica de Ambato, 2018. 